\title{
The Value of Methodological Deductivism in Argument Construction
}

\author{
FÁbio Perin Shecaira
}

Federal University of Rio de Janeiro, Faculty of Law

Rua Moncorvo Filho $n^{\circ} 8$

Rio de Janeiro-RJ

20211-340 Brazil

fabioperin@direito.ufrj.br

\begin{abstract}
Deductivism" is a broad label for various theories that emphasize the importance of deductive argument in contexts of rational discussion. This paper makes a case for a very specific form of deductivism, namely, methodological deductivism. The paper highlights the dialectical importance of advancing deductively valid arguments (with plausible premises) in naturallanguage reasoning. Sections 2 and 3 explain the various forms that deductivism has taken. Section 4 makes a case for methodological deductivism. Section 5 discusses the value of methodological deductivism in law. Section 6 concludes and acknowledges critical questions that need to be addressed more fully in future work.
\end{abstract}

Résumé: Le «déductivisme» est une étiquette qui englobe diverses théories qui soulignent l'importance de l'argument déductif dans les contextes de discussion rationnelle. On plaide en faveur d'une forme très spécifique du déductivisme, à savoir, le déductivisme méthodologique. On souligne l'importance dialectique d'avancer des arguments déductivement valides (avec des prémisses plausibles) dans les raisonnements construits dans le langage naturel. Les sections 2 et 3 expliquent les différentes formes du déductivisme. La section 4 plaide en faveur du déductivisme méthodologique. Dans la section 5 on discute de la valeur du déductivisme méthodologique en droit. Dans la dernière section on résume cet article tout en reconnaissant les questions critiques qu'on doit traiter plus profondément dans les travaux futurs.

Keywords: deductive argument, methodological deductivism, legal reasoning

(C) Fabio Shecaira. Informal Logic, Vol. 38, No. 4 (2018), pp. 471-501. 


\section{Introduction}

Deductivism is an influential account of argument that has taken various forms. Some deductivists believe all natural-language arguments ought to be interpreted as deductive arguments. Others believe that natural-language arguments ought to be evaluated according to deductive standards. A third possible form of deductivism holds that individuals formulating arguments in natural language ought to attempt to construct deductively valid arguments.

These forms of deductivism are not incompatible with one another, but they can be held and defended separately. In this paper I defend a version of the third form of deductivism listed above. I hold that real arguers ought to attempt to formulate deductively valid arguments with plausible premises-not because deductively valid arguments are intrinsically better than, say, inductively valid arguments, but because the pursuit of deductively valid arguments (with plausible premises) has positive consequences for rational argumentation. Before making this case, it should pay to take a step back and discuss the different forms of deductivism.

\section{Deductivism as an explanatory account of argument}

What follows is a fictional dialogue between friends:

A: Jones has said that the rate of unemployment will go down in the next quarter.

B: Jones is a politician, so he is not to be trusted.

A: Are you saying no politician can be trusted?

B: Well, I am sure there are some honest politicians out there.

A: But you think they are rare?

B: They are a minority.

A: Do you have any particular reason to exclude Jones from that minority? 
B: Jones is not a bad guy, but you know that election time is coming...
A: So you think that otherwise honest politicians aren't hon- est around election time?

B: They rarely are.

\begin{abstract}
A: And you're sure Jones isn't one of those rare cases? I've always found him exceptional.
\end{abstract}

B: In many ways he is. But he is also a member of the labor party, and his political future depends on his ability to convince us that the unemployment problem is under control.

This dialogue will be useful for two purposes, namely, to give a sense of what is plausible and what is questionable in the influential account of natural-language argument that Leo Groarke has called "deductivism." For Groarke (1999, p. 1), deductivism is the view that "all arguments should be understood as attempts at deductive arguments." This statement is meant to suggest that deductivism "can account for ordinary reasoning and that it can do so in a way that furthers the aims of critical discussion" (Groarke 1999, p. 14). Groarke's deductivism thus intends to explain the structure of arguments in ordinary discourse, and also hopes to contribute to dialectical exchange; i.e., Groarke' account has explanatory as well as normative ambitions. In this paper I argue that while Groarke probably overestimates the explanatory value of his account, there is still a case to be made for its normative value.

Let us go back to the hypothetical dialogue between friends. The dialogue is based on an example once used by Groarke himself:

In many cases, a natural language argument is obviously deductive...In cases where arguments are not transparently deductive, the deductivist proceeds by recognizing unexpressed premises that make them attempts at deductive inferences. This may initially sound arbitrary, but it is quite in keeping with everyday practice in dealing with obvious enthymemes like the following:

Example 3: Jones is a politician, so he is not to be trusted. 
Faced with such an argument, we have no difficulty recognizing that it contains the unexpressed premise "No politicians can be trusted." (Groarke 1999, p. 6)

There is something implausible about Groarke's idea that example 3 contains that specific unexpressed premise. There are few contexts in which a reasonable arguer would assent to it without reservation. "No politicians can be trusted" is the sort of statement which we expect from pessimistic or conspiracist individuals, or which (when uttered by otherwise reasonable people) we would normally excuse as a momentary rhetorical excess. In our hypothetical dialogue, A suspects that B probably would not want to endorse such a strong claim and thus presses B in an attempt to elicit his true beliefs. It is likely that B does not have any precise generalization in mind when he first proposes the argument to the effect that Jones cannot be trusted; a generalization only suggests itself as the dialogue develops. We are left at the end with the impression that B might assent to something like this: "Around election time, we cannot trust the claims of politicians speaking on issues directly connected to their party's official agenda." This is, of course, a much more cautious and nuanced claim than the initial hypothesis, "No politicians can be trusted."

Groarke shows some sensitivity to the concerns raised in the previous paragraph:

In assigning unexpressed premises, we can distinguish different possibilities. A "logical minimum" is the minimum claim necessary to ensure a valid inference. In some cases, it is the most plausible unexpressed premise, but there are many cases in which context or common practice clearly suggest that an arguer is committed to a stronger claim which is, in pragma-dialectical terminology, the "pragmatic optimum." In example 3 above, the logical minimum is the claim that "If Jones is a politician, then he cannot be trusted".... In the absence of some explicit indication that this idiosyncratic assumption [i.e., the logical minimum] is the basis of the proposed conclusion, it is reasonable to assume that it is the latter generalization ["No politicians can be trusted"] which drives the inference. (Groarke 1999, p. 6) 
The trouble with Groarke's argument is that what he describes as the relevant logical minimum is not the only idiosyncratic assumption that we should hesitate to ascribe to the author of the argument in example 3. We should also hesitate to burden the arguer with the overly inclusive claim, "No politicians can be trusted," in the absence of relevant clues drawn from "context or common practice" (e.g., clues to the effect that the arguer holds a grim picture of human nature). Deductivism, understood as an explanatory account of argument, thus faces the problem of interpreting ordinary arguments without attributing implausible or eccentric unexpressed premises to their authors; i.e., the real and presumably reasonable people behind the arguments.

Critics of deductivism are often troubled by its inability or unwillingness to be true to the intentions of real arguers. This problem pertains not only to the reconstruction of unexpressed premises but also to the very nature of the inferential link between premises and conclusion. The latter issue is aptly raised by David Godden in the following passage:

[T] he viability of deductivism as an interpretive thesis depends on whether people actually argue deductively or whether they appeal to other standards of justification. It depends on whether people actually change their views on the basis of other considerations. As a descriptive thesis deductivism depends solely on its accuracy in representing its subject matter, which cannot be determined without information about arguers as well as about their arguments. (Godden 2005, p. 182).

Other authors have expended significant efforts in trying to highlight the explanatory or interpretative shortcomings of deductivism. ${ }^{1}$ I mention those shortcomings fairly briefly here because I wish to focus on the prospects of the normative side of deductivism.

\footnotetext{
${ }^{1}$ Analogical reasoning is one topic of interest to this paper in respect of which deductivism has attracted significant criticism. See, for instance, Govier (2002), Guarini (2004), and Bermejo-Luque (2012).
} 


\section{Deductivism as a normative account of argument}

\subsection{The deductivist injunction}

What good is an account of natural-language argument like deductivism if it does not adequately explain ordinary reasoning? Our fictional dialogue about Jones, the politician, will help to provide an answer. B's original argument is pithy and bold: "Jones is a politician, so he is not to be trusted." The argument may be rhetorically powerful, but it is logically dubious. It is what I will call a "suggestive argument." To give a provisional definition (which will be developed ostensively in the sequel) a suggestive argument is an argument that omits potentially controversial information. By omitting such information, a suggestive argument makes it more difficult for interlocutors to assess the argument's merits and provide focused feedback. The use of a suggestive argument will often suit the purposes of an arguer like B, who, at the beginning of the dialogue, does not seem to know exactly how to justify his mistrust of politicians, or of Jones in particular. Many arguments used in everyday reasoning are suggestive in this sense: their terseness serves as a rhetorical bulwark. ${ }^{2} \mathrm{~B}$ might have been successful with his suggestive argument if he had not found in $\mathrm{A}$ an inquisitive interlocutor. A wished to know exactly what was behind B's skepticism, whether a general belief in politicians' lack of candor or something more specific. By asking questions, A put B in the intellectually difficult position of providing a general but appropriately qualified (i.e., not clearly over-inclusive) claim that could justify the dismissal of Jones's opinion as unworthy of trust.

I want to argue that the role served by A in our hypothetical dialogue could have been served equally effectively by the incorpora-

\footnotetext{
2 This is not to suggest that terseness is always used deliberately for the purpose of winning an argument. There are contexts where arguers are initially vague only because they trust that their point will eventually be clarified in the process of discussion. But it is important to notice that even when terseness is not used strategically it is apt to hinder rational debate if there are time constraints impeding protracted discussion or if interlocutors are not very inquisitive or otherwise less than fully cooperative.
} 
tion into A and B's intellectual culture of a general injunction for individuals to pursue deductively valid arguments with plausible premises in argumentation. ${ }^{3}$ We might call this the "methodological deductivist injunction," or MDI. If B had been inclined to comply with MDI from the beginning, then B would not have adopted a simple one-premise argument of an uncertain logical nature. Instead, B would have made an effort to devise a set of more precise, appropriately qualified premises that would leave little to the imagination. ${ }^{4}$ I am thinking of an argument like this: "During an election year, you cannot trust a politician who provides an optimistic prediction about a social problem that his party vowed to solve. Jones, a member of the labor party running for re-election this year, says that unemployment rates will go down. You cannot trust Jones on this." This is a deductively valid argument with quite precise and plausible premises. To be clear, the argument is deductively valid in the intuitive sense that the conclusion cannot be false if the premises are true. MDI does not promote formal validity in any sense more technical than that.

The acceptability of the first premise of the argument is open to debate. Since it was carefully constructed to avoid over-inclusion, it is not obviously false; but on the other hand, it is not obviously true. The value of MDI, however, is not in the fact that it renders arguments unobjectionable. On the contrary, when we take a deductively invalid argument and add a general premise to it for the sake of validity, we commit ourselves to new and potentially controversial information. To construct deductively valid arguments with acceptable premises is a way (and a particularly effective one,

\footnotetext{
${ }^{3}$ Note the use of "plausible premises" instead of "true premises". Critics of deductivism are quick to associate it with the idea that arguments are to be formulated in light of soundness criteria. This association is rejected by deductivists like Leo Groarke (2002, p. 278-279).

${ }^{4}$ To say that MDI is part of their intellectual culture is not only to say that B would be ready to comply with it, but also that A would expect B's compliance-and ideally would assist B in complying if he had any trouble formulating a valid argument with plausible premises on his own. MDI does not assume idealized contexts of argument where there is full cooperation, but that is not to say that it is only applicable in adversarial settings.
} 
I will argue) to trade suggestive reasoning for reasoning that is more explicit and precise. So, the point of MDI is not to put an end to disagreement, but to approach it in a way that should prove dialectically more fruitful. ${ }^{5}$

Another way to formulate MDI is perhaps as an injunction for arguers plausibly to articulate the warrant of their (otherwise suggestive) arguments; i.e., the articulate-your-warrant injunction (AWI). ${ }^{6}$ An argument warrant is understood here in the Toulminian sense of a general inference license connecting premise(s) and conclusion of an argument (Hitchcock 2003). For instance, to articulate the warrant of the argument about Jones-"Jones is a politician, so he is not to be trusted"-is to explain in general terms how one can move from the premise to the conclusion. If Jones is a politician, then he is not to be trusted is not an appropriate candidate, given its ad hoc nature. A possible warrant is if someone is a politician then s/he is not to be trusted. That, however, as we have seen, is far too broad to be plausible. The effort to articulate a plausible warrant-i.e., one which is not ad hoc but also not vulnerable to predictable counterexamples-will lead the arguer to construct an improved, less suggestive argument (in the same way as the effort to comply with MDI will do).

In principle, Toulminian warrants can be qualified by different modal qualifiers: e.g., if someone is a politician then, generally, $\mathrm{s} / \mathrm{he}$ is not to be trusted; or if someone is a politician then, proba$b l y, \mathrm{~s} / \mathrm{he}$ is not to be trusted; or if someone is a politician then, necessarily, s/he is not to be trusted. AWI and MDI are equivalent only to the extent that we understand AWI as pushing arguers to articulate deductive or non-defeasible warrants; i.e., warrants qualified by the qualifier "necessarily." In the final section, I will come

\footnotetext{
${ }^{5}$ My emphasis on the dialectical value of deductivism should not be taken to imply that MDI is only useful in contexts of literal dialogue, where arguers freely exchange arguments, objections, counter-objections, etc. On the contrary, suggestive reasoning is very problematic where terse arguments are given to an audience that has no opportunity to press the arguer to reveal controversial assumptions (think of a conference after which there is no time for questions). ${ }^{6} \mathrm{I}$ am grateful to an anonymous reviewer for suggesting the acronym.
} 
back to this issue to explain why an injunction that left it up to arguers to decide which qualifier to include in their warrants would not have the same beneficial effects of MDI.

\subsection{The effects of the injunction}

Suggestive reasoning is problematic because of two of its likely effects. One is the effect of alienating interlocutors; i.e., leaving them unconvinced yet unable to formulate precise objections or well-focused queries. The other is the effect of allowing the author of an argument to convince interlocutors who would not have been convinced had the relevant (often over-inclusive) assumptions been brought to light. Both effects are inimical, albeit for different reasons, to the goal of moving towards rational agreement. An alienated interlocutor simply does not agree. On the other hand, an interlocutor will agree, but for the wrong reasons, if his assent is secured by the omission of information that he would have found dubious. In either case, rational agreement-i.e., agreement for the right reasons-is not reached.

With respect to arguments of the sorts discussed in the next section, MDI is a promising remedy against dialectically harmful terseness and lack of preciseness. ${ }^{7}$ The remedy's effectiveness pertains to the fact that turning arguments of the relevant types into deductively valid arguments with plausible premises requires adding to them appropriately qualified general claims. The effort to bring these claims out is promoted in the name of explicitness. The effort to articulate them carefully, in order to achieve deductive validity while avoiding such common problems as over-inclusion or susceptibility to counterexamples, is promoted in the name of preciseness.

Let me be clearer about the beneficial effects for which I think MDI should be valued. Debate about any proposition can end in either (i) disagreement or (ii) agreement (in addition to partial or

\footnotetext{
7 There are alternatives to MDI that might also be proposed as effective remedies against the same problems. These alternatives will be considered in the final section, where I explain why MDI appears to be the best strategy overall.
}

(C) Fabio Shecaira. Informal Logic, Vol. 38, No. 4 (2018), pp. 471-501. 
qualified agreement; but let us put this complication aside for now). Disagreement, in turn, may (i.a) involve alienation to the extent that one of the parties has trouble articulating reasons to dissent, or (i.b) it may not involve alienation if the parties can identify with precision the assumptions about which they disagree. Agreement also comes in two forms according to whether (ii.a) it depends on the misleading omission of potentially controversial information or (ii.b) it does not.

It is difficult to say whether the incorporation of MDI within our intellectual culture would maximize agreement and minimize disagreement in the long run. For all I know, people may disagree more frequently when following MDI (given its capacity to bring out potentially controversial assumptions) than when reasoning suggestively. Clearer, on the other hand, is the impact that MDI would have on the proportion of (i.a)-type disagreement to (i.b)-type disagreement and on the proportion of (ii.a)-type agreement to (ii.b)-type agreement. In other words, complying with MDI should have the result that disagreement, whenever it occurs, will less frequently be due to alienation than it would otherwise be; and it should also have the result that agreement, whenever it occurs, will less frequently involve individuals who have been misled than it would otherwise involve. This is the meaning of the claim that MDI is dialectically beneficial.

\subsection{Similar forms of normative deductivism}

Groarke has made similar points in defending his approach to argument analysis:

We might begin by noting that the utility of deductivist argument reconstruction is highlighted by approaches to argument which are, like pragma-dialectics, dialectical and "resolution oriented"... This is a goal which is well served by deductivist reconstruction, for the unexpressed premises it identifies often expose assumptions which need to be a focus of discussion when we decide whether an argument should be accepted. (Groarke 1999, p. 8-9) 
Like Groarke, I want to emphasize the role that MDI can play in making arguers "expose assumptions which need to be the focus of discussion." Unlike Groake, however, I do not want to suggest that we need to endorse deductivism as an explanatory account of argument in order to perceive its normative payoff. My claim is not that arguers ought always to be understood by argumentation theorists as arguing deductively, but rather that arguers themselves ought to attempt to formulate deductively valid arguments with plausible premises. For the pursuit of such arguments is a promising remedy against a common tendency to rely on reasoning that vaguely suggests, instead of precisely stating, what it very well could and should be stating. Robert Ennis has come even closer than Groarke to adopting the version of deductivism defended in this paper:

I prefer a deductive view of argument reconstruction, as I shall presently explain, because it forces us to make explicit every nondeductive step and thus makes it less likely that something will slip past us. (My view is not that every argument is really deductive; rather it is that for purposes of evaluation, deductive argument reconstruction is an effective tool...) (Ennis 1982, p. 61)

The strategy that I shall describe consists of the deductive reconstruction and elaboration of an argument in such a way that every part that is not a deductively valid inference is an explicit premise. ... The idea is to expose those needed nondeductive claims... about which one can, without challenging a deductively-valid step, ask "Why so?", thus making explicit those points that might possibly require further defense. (Ennis 1982, p. 74)

There is still one notable difference between Ennis's position and the version of deductivism defended in this paper. The former pertains to how interpreters should proceed in evaluating and criticising existing arguments; the latter pertains to how arguers themselves should proceed (that is, with a view to making their arguments as open as possible to "why so" questions). One problem with Ennis's proposal is that it is futile, if not unfair, to appraise an argument by reference to a standard of justification that the arguer himself may reject. Ennis admits that not every argu- 
ment is deductive yet insists that all arguments ought to be evaluated by deductive standards. ${ }^{8}$ Fortunately, my position avoids this problem.

To sum up, "deductivism" is a broad term that has been used to describe different theoretical claims. In Section 1, I distinguished three such claims: (1) natural-language arguments ought to be interpreted as deductive arguments; (2) natural-language arguments ought to be evaluated according to deductive standards; and (3) individuals formulating arguments in natural language ought to attempt to construct deductively valid arguments with plausible premises. Groarke has defended deductivism in senses (1) and (2). Ennis argued for deductivism in sense (2). I want to make a case for deductivism in sense (3). In other words, I want to show the value of incorporating MDI-an injunction to pursue deductively valid argument with plausible premises-in natural-language reasoning.

Deductivism in sense (3) is not affected by many of the objections that have been put forward by critics of deductivism in senses (1) and (2). Most importantly, since deductivism in sense (3) is normative, not explanatory, it cannot be accused of reductionism. Normative deductivism does not attempt to show that what seem like inductive or otherwise non-deductive natural-language arguments are always, often in virtue of eccentric implicit premises, covertly deductive arguments. Rather, normative deductivism enjoins arguers to attempt to substitute deductively valid arguments with plausible premises for other (genuinely non-deductive) forms of argument.

Notice that deductivism in sense (3) may itself come in different varieties. Some normative deductivists think that (3.a) individuals ought to attempt to formulate deductively valid arguments because "good reasoning in logic generally is minimally a matter of deductively valid inference" (Jacquette 2009, p. 189). I, on the other

\footnotetext{
${ }^{8}$ Ennis's position has evolved since his 1982 paper. More recently, Ennis has argued against the very idea that arguments should be classified as inductive or deductive before being appraised. See Ennis (2001).
} 
hand, think that (3.b) individuals ought to attempt to formulate deductively valid arguments with acceptable premises because of the positive dialectical consequences of this exercise. The point of this paper is not to show that deductively valid arguments are intrinsically better than non-deductive arguments. I have no fetish for deductive validity in itself. The pursuit of deductively valid arguments with acceptable premises is only valuable as a means to the end of rational agreement. The form of deductivism defended here is thus normative in the sense that it is instrumental to the pursuit of other valuable goals. This is why I avoid the label "deductivism" (which might imply something like 3.a) and use for my position the label "methodological deductivism." The point is to make very clear that I value the pursuit of deductive validity as a means to other ends, as a method that is apt to enhance the quality of argumentation.

\section{Developing the case for deductivism}

\subsection{Analogical and pro-and-con reasoning}

Following Bruce Waller (2001), I have argued that the best analogical arguments in ethics and law are those that express, or at least provide the interpreter with enough elements to reconstruct, the normative principle tying together source and target of the analogy (Shecaira 2013). Here is a familiar example: "It is not morally wrong to smoke tobacco. Marijuana and tobacco are substances with similar effects. So, it is not morally wrong to smoke marijuana." This is a suggestive analogical argument. It indicates that there are similarities between smoking marijuana and smoking tobacco, but it does not specify those similarities. The audience is simply meant to "see" the similarities. But what if certain members of the audience do not intuitively find the two courses of action similar for ethical purposes? Would they be wrong to reject the argument? And if they were to reject the argument, on what particular grounds should they do so? 
Rational debate would be furthered by a willingness to be more precise and explicit. Following MDI, the author of the analogy might reason like this: "[1] It is not morally wrong to smoke tobacco. [2] Marijuana and tobacco have similar effects, since they are mild drugs that do not bring imminent danger to users or those with whom they interact. [3] It is not morally wrong to use any substance that does not bring imminent danger to users or those with whom they interact. [4] So, it is not morally wrong to smoke marijuana." This explicit version of the analogical argument contains a deductively valid inference from claims [1], [2], and [3] to claim [4]. The principle expressed as claim [3] is something into which the arguer's audience can really sink their teeth. If they disagree with it they will not feel alienated (as they would feel if they simply failed to "see" the force of the suggestive analogy). They will be able to articulate definite objections and will be expected to produce counter-examples if they want to impugn the principle for being overbroad.

The same basic point can be made regarding another widely discussed pattern of natural-language reasoning. For arguments of this other type also tend to be put forward suggestively, and, again, MDI is a promising remedy for the problem. Consider Carl Wellman's discussion of third-pattern conductive argument (or simply, pro-and-con argument), "in which some conclusion is drawn from both positive and negative considerations" (Wellman 1971, p. 57). One of Wellman's examples is this: "[A]lthough your lawn needs cutting, you ought to take your son to the movies because the picture is ideal for children and will be gone by tomorrow." (Wellman 1971, p. 57) This is a fairly banal argument, unlikely to raise controversy. The ensuing dialectic will probably not be hindered by the fact that the author of the argument does not take the time to explain why the reasons for taking the child to the movies override the reasons for cutting the lawn. But consider a different example of pro-and-con argument, this time in the legal domain: 
Tortfeasors are liable to pay full reparative damages to those whom they tortiously injure;

Jones tortiously injured Smith to the tune of $\$ 100$;

but the tort was also the breach of a contract between Jones and Smith;

the contract provided for maximum reparative damages of $\$ 50$ for any breach;

contracts and the limits on damages they set are legally binding as between parties to the contract;

and it is unjust to let someone avoid a legally binding contractual limit on damages by instead suing the other contracting party in tort;

Therefore,

Jones is liable to pay Smith only $\$ 50$ in reparative damages. ${ }^{9}$

Wellman's example of conductive argument is suggestive while Gardner's is explicit: the italicized premise explains, by reference to justice, why a contractual duty should prevail in respect of a conflicting duty under tort law. This premise, which renders the argument deductively valid, ${ }^{10}$ will naturally be subject to debate, since the audience may question the conception of justice at issue by, e.g. asking whether it would not also be unjust to allow someone to formulate a contract with a strict cap on damages only to avoid the liability that would result from a premeditated tort. The point is that no such focused objection would be available to the audience if the relevant premise had been omitted from the argument (as in the case of Wellman's example). For the audience would not know by what criteria the arguer adjudicated between the relevant pro-and-con considerations.

\footnotetext{
${ }^{9}$ The example is taken from John Gardner (2012, p. 187).

${ }^{10}$ I assume that, in this context, to describe a decision as "unjust" is to characterize it as wrong all-things-considered.
} 


\subsection{Replies to possible objections}

MDI is a wise policy in any context where there is a significant risk that terseness will be used as a rhetorical device hindering rational debate. This leaves open the possibility that there are contexts where suggestive arguments may not be harmful to rational debate. One type of context that comes to mind involves individuals with proper statistical training using arguments whose inductive strength can be measured numerically. We should expect this sort of arguer (and this sort of audience) to know enough about the structure and limitations of their non-deductive arguments.

Does this concession render methodological deductivism too modest or trivial? It is one thing to urge individuals to argue deductively; it is another thing to urge them to do so only to the extent that they are not adept at arguing inductively. In response to this objection, I should say that the significance of MDI derives from the fact that it targets a class of arguments that is of particular concern to contemporary argumentation theorists and informal logicians. The "distinctive province" (Johnson 2011, p. 19) of informal logic has been defined as encompassing precisely those arguments that are neither deductive nor inductive (in the sense associated with statistical reasoning). The arguments on which I want to focus-namely, analogical and pro-and-con arguments-are arguments of this special, neither-deductive-nor-inductive type. Proposing methodological deductivism in respect of this class of arguments should prove controversial enough.

In fact, it may be no coincidence that the risk of poor reasoning is greater with respect to arguments forming the subject matter of informal logic. Informal logicians have been very concerned with promoting "pluralism," that is, with showing that there are many different forms of argument that are deserving of logical respect. In a sense, they are right, since not every good argument is deductively valid. Yet, arguments of the sorts studied by informal logic are often misused from a dialectical point of view, and sometimes they are misused, I surmise, because informal logic has made it easier for arguers to co-opt the banner of pluralism in attempts to shield poor reasoning from critical scrutiny. Trudy Govier has said, while 
discussing analogical arguments in ethics, that "[t]he trick about analogies-and their charm as well, I think-is that we are often able to see or sense important resemblances between cases without being able to spell them out exhaustively in just so many words" (Govier 1989, p. 148). My worry is that arguers may feel encouraged to celebrate as "charming" what in effect are underdeveloped and alienating arguments. This happens both with analogical arguments that do not list relevant similarities between cases and with pro-and-con arguments that do not describe criteria for balancing conflicting reasons. ${ }^{11}$

Let us now consider a different objection: it may be thought that MDI is too demanding for real arguers. MDI is a prescription about how individuals ought to argue. Presumably, in some sense "ought" implies "can." We should not ignore the fact that arguers are often unable to provide explicit and precise arguments. For instance, momentous decisions in the public or private domain are often made in the face of severe time constraints, lack of insight or limited foreknowledge. There may be good reason to encourage an arguer facing such obstacles to make a decision on the basis of suggestive reasoning. Decisions can be preceded by more or less rational deliberation; when the ideal, explicit sort of deliberation is impractical, a proponent of MDI should accept the second-best alternative. As Fabio Paglieri and John Woods have put it, "Insofar as our resources are scant, it is highly rational to stick to the most relevant facts while arguing." (Paglieri and Woods 2011, p. 480)

This is a rather banal sort of pragmatism that should be expected from any theorist proposing a normative account of argument: there are circumstances in which arguers may be permitted to cut corners. However, some readers may suspect that MDI is too demanding of arguers in a different sense. My comments concerning analogical and pro-and-con reasoning assume the epistemic availability of moral principles. To formulate a good analogical argument in

\footnotetext{
${ }^{11}$ My claim is not that informal logic has done more harm than good. It is clear informal logic has improved our understanding of natural-language reasoning. The point is that there is a feature of informal logic-namely, its often incautious emphasis on pluralism-that serves to offset some of its benefits.
}

(C) Fabio Shecaira. Informal Logic, Vol. 38, No. 4 (2018), pp. 471-501. 
ethics is not only to compare cases plausibly, but also to explain under what moral principle the cases fit. Similarly, to offer a good pro-and-con argument in ethics is not simply to choose among conflicting considerations but to explain why (i.e., by reference to what moral criteria) the overriding considerations should prevail. The problem is that moral particularism is an important ethical position these days, ${ }^{12}$ which suggests that my account of argument will be controversial insofar as it takes sides on a complex debate in moral philosophy.

In defence of MDI, it should be noted that the assumption made here in favour of ethical generalism is not idiosyncratic in the context of informal logic. Even if particularism is a viable ethical theory, it is a revisionist theory. For instance, it does not seem able to account for everyday reasoning to the extent that it fails to explain important features of analogical argument (Guarini 2010). Even authors who reject deductivist analyses of analogical argument have agreed that real analogical arguments, for all their customary suggestiveness, imply the existence of some principle, though often an indefinite one that the arguer may not be ready to specify and thus cannot be considered by interpreters to figure as an unexpressed premise (Govier 1989, p. 148). Methodological deductivism does, in fact, reject moral particularism; it does not assume, on the other hand, that plausible, suitably qualified moral principles are easily devised in the context of rational debate. It is known by both theorists and laypeople that prima facie plausible moral principles are always subject to unforeseen counterexamples. Formulating a suitable moral principle may be difficult, but rational debate has little to gain from the idea that principles should not be sought.

Two more remarks should be made in connection with the issue of how demanding MDI is. First, notice that it does not propose universal reform in natural-language argumentation. The focus of the paper has been on rational debate; i.e., on dialectical exchanges between individuals who are committed to the goal of attaining

\footnotetext{
${ }^{12}$ For an overview, see Dancy (2017).
} 
rational agreement. Individuals who have such a goal (as opposed to, say, individuals arguing casually or playfully) should be willing to put in some effort in order to avoid alienating and misleading their interlocutors. Think of academics, journalists, social critics, judges, and other professionals who are expected to provide careful arguments in defense of their views, and who usually have time and incentive to prepare those arguments in writing or for oral delivery in a public forum. These individuals are definitely within the purview of MDI because they are good examples of individuals who should enter into debate with the goal of seeking rational agreement.

Second, the effort MDI expects of such individuals is not as great as it may seem. One possible concern is that once someone becomes committed to MDI, they will feel obliged to justify every premise that proves contentious by means of a further deductively valid argument with its own plausible premises. But where would one stop? In response to this concern, two points should be made. Although MDI enjoins arguers to attempt to formulate deductively valid argument with plausible premises, it does not say that justification by further deductively valid argument is the relevant criterion of premise plausibility. Plausible premises, such as plausible moral principles in non-suggestive analogies, are those that are carefully formulated so as to avoid the common problem of overinclusion or refutation by counter-example. So, MDI does not enjoin arguers to pursue deductively valid argument indefinitely but to go one step further than they normally would. MDI does not ask individuals to be maximally explicit and precise but expects them to take a realistic step in that direction.

\section{Deductivism in law}

\subsection{Deductive argument in contemporary legal theory}

It may come as a surprise to informal logicians that many legal theorists assign to deductive argument a central role in legal reasoning. Legal thinking is suffused with deductivist ideas, and it is 
useful to bring these ideas to light in order to provide further illustration of the beneficial effects of MDI. Juristic discussion of this topic often centers on the idea of the (so-called) "legal syllogism" and the conditions for its justification. ${ }^{13}$ The legal syllogism is generally understood as a deductive, two-premise argument beginning with a general norm and concluding with an individual one. Consider an example, to which we may refer as "Simple Legal Syllogism"14:

Tortfeasors are liable to pay full reparative damages to those whom they tortiously injure.

Jones tortiously injured Smith to the tune of $\$ 50$.

Therefore,

Jones is liable to pay Smith $\$ 50$ in reparative damages.

Neil MacCormick (2009, Chapter 4) has argued that the syllogism is central to legal reasoning. Legal debate, for MacCormick, is structured around the syllogism. Ideally, a judge will justify a ruling by showing that it follows inexorably from a valid legal norm and a proved set of facts. But even when no such straightforward inference is at hand, legal actors still structure their argumentation in a way that reveals their fundamental belief in the justificatory power of the syllogism.

Why might the syllogistic justification of a ruling fail to be straightforward? The reasons are various, but they can be sorted into two general types, according to the distinction between internal and external justification. To begin with the former, not every syllogism is as clearly valid as Simple Legal Syllogism. The general norms that figure as premises of legal syllogisms often employ vague or otherwise obscure expressions under which the facts of the case may not be clearly subsumable. Consider this argument:

\footnotetext{
${ }^{13}$ See, for instance, Wróblewski (1971), MacCormick (2009), and Alexy (2010).

${ }^{14}$ The example is taken, with minor modifications, from Gardner (2012, p. 186).
} 
Anyone who takes a vehicle into the public park is liable to pay a $\$ 50$ fine.

Jones took roller skates into the public park.

Therefore,

Jones is liable to pay a $\$ 50$ fine

"Vehicle" is vague, and roller skates are a borderline case. The syllogism, as it stands, is not valid. In other words, it raises an issue of internal justification. External justification, on the other hand, pertains not to the validity of the syllogism but to the acceptability of its premises. Questions of external justification appear, for instance, when issues are raised about the evidence bearing on the truth of the factual premise, or about the legal validity of the norm in the major premise. A syllogism is beyond reproach only when it is both internally and externally justified.

MacCormick argues that the syllogism typically takes center stage in the legal process, being surrounded by supporting nonsyllogistic arguments whenever questions of internal and external justification are raised. The arguments surrounding the syllogism are not necessarily deductive. Empirical considerations are adduced in support of the factual premise; other kinds of non-deductive, and for the most part non-empirical, arguments are used to support the normative premise and to establish the validity of the syllogism as a whole. To anticipate what is to come in the next section, analogies are one prominent sort of the non-deductive, non-empirical arguments at issue. Imagine an argument to the effect that roller skates could be just as dangerous to pedestrians in the park as other undisputed instances of vehicles: cars, motorcycles, etc. An analogical argument such as this might be used to justify the conclusion that (for legal purposes) skates are vehicles.

From the point of view of jurists, there is nothing radical about MacCormick's position. He claims that the syllogism plays a central role in legal reasoning, but by no means does he suggest that legal reasoning should, or even could, be limited to the syllogism. Ironically perhaps, MacCormick calls himself a "deductivist." 
What I understand by deductivism goes beyond MacCormick's position, and should prove more controversial. To put it in the technical terms introduced in this section, my view is that, so far as possible, legal syllogisms ought to be internally and externally justified by means of deductively valid arguments with plausible premises. The main reason to adopt this view is that the increase in explicitness and preciseness (which should follow from compliance with MDI) is apt to enhance the rational character of legal debate. ${ }^{15}$ The argument made in the previous sections is as relevant for legal debate as it is for non-legal debate.

\subsection{Applying MDI in law}

In a recent book, John Gardner (2012) collects several essays exploring the subject of legal reasoning. Gardner expresses no interest in deductivism (in either MacCormick's sense or mine) but offers some relevant insights and examples. Gardner develops a distinction (made originally by Joseph Raz) between reasoning about the law and reasoning with or according to law. The former is reasoning about what the law already is, about what existing legal norms establish in respect of a given case. The latter is reasoning that takes valid legal norms as premises but combines them with moral premises in order to arrive at a conclusion about how to settle a legal case. A legal actor undertakes reasoning according to law typically in circumstances of legal indeterminacy, when the existing legal norms alone cannot provide a unique solution to the case at hand.

One of Gardner's examples of reasoning about the law is precisely the argument dubbed earlier Simple Legal Syllogism. Gardner's examples of reasoning according to law, on the other hand, are examples of arguments that would be used by legal actors in

\footnotetext{
15 There are also political reasons for complying with MDI in law. The ideal of the rule of law recommends (inter alia) that authorities justify their decisions in a way that will allow legal subjects to understand their reasons and (if necessary) contradict them on appeal. The political side of MDI will not be discussed in this paper.
} 
default of a simple, syllogistic justification of a legal conclusion. ${ }^{16}$ They are arguments needed in order to justify (either internally or externally) a controversial legal syllogism. Consider "Legal Syllogism 2":

Contracts and the limits on damages they set are legally binding as between parties to the contract.

Jones tortiously injured Smith to the tune of $\$ 100$ thus breaching a contract between them which provided for maximum reparative damages of $\$ 50$ for any breach.

Therefore,

Jones is liable to pay Smith only $\$ 50$ in reparative damages.

In the light of the legal norm about torts that figured as a premise of Simple Legal Syllogism, the external justification of Legal Syllogism 2 is questionable: how could the norm about contracts and their limits settle the case of Jones versus Smith when there is a conflicting norm about torts that is also relevant to the controversy? The matter requires a more complex argument, such as "Legal Proand-Con":

(1) Tortfeasors are liable to pay full reparative damages to those whom they tortiously injure (the norm from Simple Legal Syllogism)

(2) Contracts and the limits on damages they set are legally binding as between parties to the contract (the norm from Legal Syllogism 2).

(3) Jones tortiously injured Smith to the tune of $\$ 100$ thus breaching a contract between them which provided for maximum reparative damages of $\$ 50$ for any breach.

\footnotetext{
${ }^{16}$ In fact, Gardner's examples of reasoning according to law are examples of analogical and pro-and-con arguments. He may share my impression that these forms of argument are frequently used by legal actors when the law is unclear (due to vagueness, ambiguity, etc.) or contains antinomies.
} 
(4) It is unjust to let someone avoid a legally binding contractual limit on damages by instead suing the other contracting party in tort.

Therefore,

(5) Jones is liable to pay Smith only $\$ 50$ in reparative damages. ${ }^{17}$

On the assumption that there is no straightforward legal criterione.g., lex posterior derogat legi priori-available to resolve the conflict between legal norms, a legal actor is liable to weigh the conflicting norms by appeal to non-legal criteria. Legal Pro-andCon has the virtue of exposing the relevant criteria in (4). Why the virtue? It is often the case that legal actors do not make weighing (or balancing) criteria explicit. They acknowledge a conflict between legal norms (or values or rights) and affirm that one should prevail over the other in the particular case without giving a principled explanation as to why that should be. In the case of Legal Proand-Con, that explanation is given in (4), and (4) will naturally draw attention to itself.

Gardner gives us another example of reasoning according to law. Call it "Legal Analogy":

(1) The Civil Rights Act of 1964 gives everyone the legal right not to be discriminated against in respect of employment on the ground of his or her sex.

(2) Denying a woman a job on the ground of her pregnancy is morally on a par with discriminating against her on the ground of her sex, even though there is no exact male comparator to a pregnant woman that would allow the denial to count as sex-discriminatory in the technical sense.

\footnotetext{
${ }^{17}$ Legal Pro-and-Con appeared earlier in this paper, as an example of an explicit (as opposed to a suggestive) pro-and-con argument.
} 
Therefore,

(3) Women have a legal right not to be denied a job on the ground of their pregnancies.

(4) This woman P has been denied a job by D on the ground of her pregnancy.

Therefore,

(5) D owes $\mathrm{P}$ a job. ${ }^{18}$

Legal Analogy is actually a compound argument made up of two linked inferences, only the first of which is, strictly speaking, an analogical argument. The second inference is a legal syllogism. The normative premise of the syllogism, premise (3), does not express a clearly valid legal norm under the Civil Rights Act and that is the reason why its justification is given by means of a further argument which amounts to an analogy between discrimination in respect of employment on the ground of sex and discrimination in respect of employment on the ground of pregnancy. As is often the case in legal argumentation, the analogy is only suggestive, since we are not told why the two cases are similar. Should it be obvious to everyone who hears the argument that discrimination on the ground of pregnancy (which will hinder one's capacity to work at least for a period) is morally on a par with discrimination on the ground of sex (which in itself has no relation to work capacity)? The analogy, being suggestive, gives us little clue as to how its author would deal with conceivable objections along these lines.

To sum up, analogical and pro-and-con arguments are often proposed in non-deductive form in attempts to justify legal syllogisms. To the extent that we wish legal debate to live up to standards of frank, focused, rational argument, we should advise that analogical and pro-and-con arguments be formulated in accordance with MDI.

\footnotetext{
18 The example is taken, with minor modifications, from Gardner (2012, p. 3940).
} 


\section{Conclusion}

This paper makes a case for methodological deductivism, understood as an injunction for arguers to attempt to substitute deductively valid arguments with plausible premises for terse, "suggestive" forms of argument. The injunction put forward in this paper, MDI, serves to promote explicitness and preciseness in naturallanguage argumentation, thereby furthering the goals of rational debate. To the extent that legal actors take part in rational debate, they should also heed MDI.

The argument made here for deductivism has limitations that must be acknowledged. It is essentially a teleological argument to the effect that MDI is a means for achieving an important dialectical goal. But teleological arguments face a challenging set of critical questions that I have not yet addressed. Douglas Walton and Giovanni Sartor (2013, p. 121-123) give a helpful account of teleological schemes for reasoning towards practical decisions:

1. I (an agent) have a goal G.

2. Carrying out this action A is a means for me to realize G.

3. Therefore, I ought (practically speaking) to carry out this action $\mathrm{A}$

This scheme is accompanied by a set of critical questions, including: "What other goals do I have that should be considered that might conflict with my goal G?"; "What alternative actions to my bringing about $A$ that would also bring about $G$ should be considered?"; "Among bringing about A and these alternative actions, which is arguably the most efficient?" These questions are not easily answered when thinking of the teleological argument that has been given in this paper for MDI (where mitigation of the problems related to suggestive reasoning takes the place of goal $\mathrm{G}$, and action A corresponds to the type of argument construction recommended by MDI).

Here is brief sketch of answers to be developed in future work. I am confident that although rational agreement is not the only goal that an account of argument may hope to serve, it is an important 
goal over which the familiar alternatives have no clear priority. For instance, MDI is not a good means for the goal of being rhetorically effective in many contexts. But why would anyone assume that persuasiveness has priority over rational agreement? More important, to my mind, is the consideration that there may be other strategies that compete with MDI as means for furthering its avowed goal. If the point of MDI is to further rational agreement by motivating explicitness and preciseness in argumentation, why not simply enjoin individuals to be as explicit and precise as possible in their arguments? Why take the circuitous route of advising the construction of deductively valid arguments with plausible premises? The trouble with urging explicitness and preciseness tout court is that it is quite a vague way to guide reasoners through what is not an intuitive task. Yes, one must be explicit and precise-but how? If the arguer does not know how, can he always count on having cooperative interlocutors who will assist in this task? MDI is quite specific and can be followed by anyone with an elementary grasp of logic.

A second strategy that may compete with MDI, and which might fare well with respect to the guidance criterion, is the recommendation that reasoners construct their arguments in accordance with the relevant arguments schemes and associated critical questions elaborated by argumentation theorists. ${ }^{19}$ Thinking through critical questions is a way of anticipating potential objections and refining the argument accordingly. Indeed, it is difficult to say which would be more effective for the purposes of rational agreement, whether complying with MDI or anticipating critical questions. Both strategies may work well against our tendency to omit or avoid potentially controversial assumptions. Empirical research might help to shed light on this question; but in the absence of the research, here are some provisional remarks.

One advantage of MDI is the fact that it can be used in different contexts, where different argument forms are apt to be instantiated. In this paper, I have tried to show the value of MDI for analogical

\footnotetext{
${ }^{19}$ For a thorough exploration of this approach, see Douglas Walton et al. (2008).
} 
and pro-and-con reasoning, but there is no reason to doubt that suggestive arguments of yet other forms might be converted according to MDI with similar payoff. The argument about Jones in the dialogue at the beginning of the paper is also a conductive argument (although not a third-pattern conductive argument), and it also benefitted from being converted. Suggestive arguments of different forms (e.g., inference to the best explanation, argument from expert opinion) could also benefit.

The appropriate scheme with its accompanying critical questions, on the other hand, will vary according to the sort of argument one wishes to advance. The critical questions to be addressed when one constructs an analogy are different from the critical questions pertaining to pro-and-con reasoning, which are different from the critical questions pertaining to inference to the best explanation, etc. So, one disadvantage of this strategy is that, albeit precise, it is unwieldy compared with MDI. It is unwieldy in two different senses. First, while MDI is but one injunction potentially relevant for a variety of argument forms, the alternative is a set of injunctions whose content varies depending on the form of the argument to be advanced. Second, using schemes and their associated critical questions requires an ability to locate one's intended argument within an argument taxonomy before addressing the pertinent critical questions. But argument classification is a divisive subject. Theorists disagree about how many types of argument there are and how they relate to each other. Compared with MDI, the schemeplus-critical-questions approach requires mastering more technical concepts and also taking a position with regard to controversial issues in the argumentation literature. All that before an argument can even be made.

In Section 3, I indicated that MDI can also be rendered as an injunction for arguers to articulate plausible deductive warrants for their otherwise suggestive arguments. A question that deserves to be considered at this point is whether MDI is superior to an injunction for arguers to articulate their warrants, allowing them to qualify their warrants as they wish. What is so special about deductive warrants after all? Is the articulation of a defeasible warrant not 
good enough for the purposes of clarity and completeness? I submit deductive warrants are preferable-not because of intrinsic superiority, of course, but in terms of their dialectical benefits. The pursuit and articulation of plausible deductive warrants is likely to have beneficial effects that the pursuit of other kinds of warrant would not have.

To see why, let us go back to the Jones argument: "Jones is a politician, so he is not to be trusted." It is far too comfortable for the author of this argument to claim that it rests on the inference license that if someone is a politician then, probably, generally or presumably, s/he is not to be trusted. These vague qualifiers (which have little to do with statistical probability) allow the arguer to avoid any number of counterexamples to the generalization. An attentive interlocutor could point to different undisputed examples of honest politicians only to hear the author of the argument parry the objection glibly: "but I never said all politicians are dishonest...". When deductive warrants are at stake, this common rhetorical move is simply unavailable. Deductive warrants are always subject to refutation through the presentation of counterexamples. This possibility induces the arguer abiding by MDI to formulate nuanced warrants that are less susceptible to the charge of overinclusion.

To be sure, nuanced deductive warrants are never completely free from objections through counterexample. To articulate a deductive warrant is to put forward a claim that has a good chance of being falsified in the light of new cases, cases that the arguer was unable to anticipate. But that is not a problem from the dialectical point of view. The purpose of MDI, as I have been concerned to explain, is not to help arguers to construct infallible arguments, but to create an incentive for them to formulate precise and explicit arguments that will further the goal of rational agreement.

Acknowledgements: I am grateful to audiences in the European University Institute (International Workshop on Reason-Giving in Law, April 2017) and McMaster University (Philosophy Department Speaker Series, September 2018). Special thanks are due to Stefano Bertea (who suggest- 
ed to me the label "methodological deductivism"), Pat Bondy, Ben Hamby, Luis Duarte d'Almeida, David Hitchcock, Giocanni Sartor, Katharina Stevens, and Noel Struchiner.

\section{References}

Alexy, Robert. 2010. A Theory of Legal Argumentation. Oxford University Press.

Bermejo-Luque, Lilian. (2012). A Unitary Schema for Arguments by Analogy. Informal Logic 32(1): 1-24.

Dancy, Jonathan. 2017. Moral Particularism. In The Stanford Encyclopedia of Philosophy (Winter 2017), ed. Edward N. Zalta, URL accessed 28 March 2018: http://plato.stanford.edu/ /entries/moralparticularism/.

Ennis, Robert. 1982. Identifying Implicit Assumptions. Synthese 51(1): 61-86.

Ennis, Robert. 2001. Argument Appraisal Strategy: A Comprehensive Approach. Informal Logic 21(2): 97-140.

Gardner, John. 2012. Law as a Leap of Faith. Oxford University Press.

Godden, David. 2005. Deductivism as an Interpretive Strategy: A Reply to Groarke's Recent Defense of Reconstructive Deductivism. Argumentation and Advocacy 41(3): 168-183.

Govier, Trudy. 1989. Analogies and Missing Premises. Informal Logic 11(3): 141-152.

Govier, Trudy. 2002. Should a priori Analogies Be Regarded as Deductive Arguments? Informal Logic 22(2): 155-157.

Groarke, Leo. 1999. Deductivism within Pragma-Dialectics. Argumentation 13(1): 1-16.

Groarke, Leo. 2002. Johnson on the Metaphysics of Argument. Argumentation 16(3): 277-286.

Guarini, Marcello. 2004. A Defence of Non-deductive Reconstructions of Analogical Arguments. Informal Logic 24 (2): 153-168

Guarini, Marcello. 2010. Particularism, Analogy, and Moral Cognition. Minds and Machines 20(3): 385-422. 
Hitchcock, David. 2003. Toulmin's Warrants. In Anyone Has a View: Theoretical Contributions to the Study of Argumentation, ed. Frans van Eemeren, J. Anthony Blair, and Charles Willard, 69-82. Dordrecht: Springer.

Jacquette, Dale. 2009. Deductivism in Formal and Informal Logic. Studies in Logic, Grammar and Rhetoric 16(29): 189- 216.

Johnson, Ralph. 2011. Informal Logic and Deductivism. Studies in Logic 4 (1): 17-37.

MacCormick, Neil. 2009. Rhetoric and the Rule of Law. Oxford University Press.

Paglieri, Fabio and John Woods. 2011. Enthymematic Parsimony. Synthese 178(3): 461-501.

Shecaira, Fábio Perin. 2013. Analogical Arguments in Ethics and Law: A Defence of a Deductivist Analysis. Informal Logic 33 (3): 406-437.

Waller, Bruce. 2001. Classifying and Analyzing Analogies. Informal Logic 21(3): 199-218.

Walton, Douglas, Chris Reed, and Fabrizio Macagno. 2008. Argumentation Schemes, Cambridge University Press.

Walton, Douglas and Giovanni Sartor. 2013. Teleological Justification of Argument Schemes. Argumentation 27(2): 111-142.

Wellman, Carl (1971). Challenge and Response. Justification in Ethics. Southern Illinois University Press.

Wróblewski, Jerzy. 1971. Legal Decision and its Justification. In Proceedings of the World Congress for Legal and Social Philosophy, ed. Hubert Hubien, 409-419. Brussels: Bruylant. 